BMJ Open Sport \& Exercise Medicine

\section{Injury trend analysis in the Japan national swim team from 2002 to 2016: effect of the lumbar injury prevention project}

To cite: Matsuura $\mathrm{Y}$, Hangai $\mathrm{M}$, Koizumi K, et al. Injury trend analysis in the Japan national swim team from 2002 to 2016 : effect of the lumbar injury prevention project. BMJ Open Sport \& Exercise Medicine 2019:5:e000615. doi:10.1136/ bmjsem-2019-000615

Accepted 13 October 2019

\section{Check for updates}

(c) Author(s) (or their employer(s)) 2019. Re-use permitted under CC BY-NC. No commercial re-use. See rights and permissions. Published by BMJ.

${ }^{1}$ Faculty of Sport Sciences, Waseda University, Tokyo, Japan ${ }^{2}$ Medical Committee, Japan Swimming Federation, Tokyo, Japan

${ }^{3}$ Department of Sports Medicine Japan Institute of Sports Sciences, Tokyo, Japan ${ }^{4}$ College of Sports Sciences, Nihon University, Tokyo, Japan ${ }^{5}$ Japan Swimming Federation, Tokyo, Japan

${ }^{6}$ Faculty of Law, Toyo University, Tokyo, Japan

Correspondence to Dr Koji Kaneoka; kaneoka@waseda.jp

\section{ABSTRACT}

Objectives This study aimed to clarify the trends of injury occurrence in the Japan national swim team for 15 years and to evaluate the effectiveness of the lumbar injury prevention project. It also aimed to verify the incidence of swimming-related injuries among swimmers by sex, age and swimming style.

Methods The target group comprised 488 swimmers who participated in the Olympics, Asian Games and Universiade from 2002 to 2016; we compiled data for the total number of injuries in each body part. The lumbar injury prevention project started in 2008 and included two components (deep trunk muscle exercises and evaluation of lumbar disc degeneration using MRI). We analysed the prevalence of lumbar injury before (2002-2008) and after (2009-2016) implementation of the lumbar injury prevention project by $\chi^{2}$ test. We compared age, sex and swim strokes between the injured and non-injured groups by $\chi^{2}$ test and unpaired t-test.

Results The most common injury site was the lower back, followed by the shoulder and knee. The lumbar injury prevalence was significantly lower after implementation of the prevention project ( $23.5 \%$ vs $14.8 \% ; p<0.05)$. Shoulder injuries were common in backstroke swimmers. The injury rate was significantly higher in female than in male swimmers. The injured group was significantly older than the non-injured group.

Conclusions Lumbar injury prevention intervention might be effective to prevent lower back injury in swimmers. Injury risk factors included female and old age; younger female athletes should prevent the development of injuries as they mature.

\section{INTRODUCTION}

A lower prevalence of incidence injury is associated with swimming compared with other sports, but the prevalence of overuse injury is high. ${ }^{1-3}$ Furthermore, for swimming, the incidence of injury is higher during training than during competition. ${ }^{4}$

The most common injured body part in swimmers is the shoulder. ${ }^{5-12}$ The prevalence rate of shoulder injuries in swimmers can be as high as $91 \%$ in competitive swimmers. ${ }^{5} 1314$

\section{What are the new findings?}

- We analysed the injury trends for the Japan nationa swim team from 2002 to 2016 and found that the lumbar injury rate significantly decreased after implementation of the lumbar injury prevention project.

- Since the rates of knee joint and shoulder joint injuries showed an increasing trend during this period, preventive measures against these injuries are required in the future.

- With respect to swimming strokes, the rate of shoulder injuries was significantly higher in athletes competing in the backstroke category.

- As both female and older athletes have a higher risk of injury, prevention interventions should commence at a young age, especially for female athletes.

How might it impact on clinical practice in the near future?

Deep trunk muscle training is effective for the prevention of lower back injury in swimmers.

In the future, preventive measures against shoulder and knee joint injuries must be implemented.

The second and third most commonly injured parts were the lumbar and knee. ${ }^{15}$ Prien $e t$ al reported a comparison of results from three FINA World Championships; the most common injuries were shoulder sprains $(5.7 \%)$ and muscle cramps in the lumbar spine area $(5.7 \%))^{3}$ In contrast, lumbar injury was the most common injury among the Japan swimmers. ${ }^{16}$ In an epidemiological survey, approximately $70 \%$ of elite Japan swimmers had disc degeneration. ${ }^{17}$ Furthermore, the prevalence of disc disorders in college swimmers was greater than that in other athletes. ${ }^{18}$ Therefore, the Japan Swimming Federation Medical Committee launched the lumbar injury prevention project in 2008 with the cooperation of the Japan Institute of Sports Science (JISS). This project has 
been implemented for all the Japan national swimmers and candidates since 2008. In this project, the extent of degeneration of the lumbar disc was evaluated by MRI of the lumbar spine, and instruction regarding deep trunk muscle training that is effective for the prevention of lumbar injury was provided. However, as there is no study on the prevalence of injuries in national swimmers after introduction of the project, the effectiveness of the project is not clear. In addition, a study was conducted on the prevention of lower back injury in the general public; however, there are only a few studies in athletes. ${ }^{19}$ The success rate for the prevention of low back injury in swimmers is unknown. This study aimed to document the trends of injury occurrence in the Japan national swim team for 15 years and to evaluate the effectiveness of the lumbar injury prevention project.

\section{METHODS}

\section{Participants}

A total of 488 Japan national swimmers who participated in the Olympics (2004, Athens; 2008, Beijing; 2012, London; 2016, Rio de Janeiro), Asian Games (2002, Busan; 2006, Doha; 2010, Guangzhou; 2014, Incheon) or Universiade (2003, Daegu; 2005, Izmir; 2007, Bangkok; 2009, Beograd; 2011, Shenzhen; 2013, Kazan; 2015, Gwangju) from 2002 to 2016 were included in this study.

\section{Injury surveillance}

We collected data for the swimmers for the period 20022016 from the medical clinic database in the JISS. We compiled the injuries diagnosed by orthopaedic surgeons at the precompetition medical check-up before the international competitions.

Injuries were categorised by the body parts according to the IOC for injury surveillance ${ }^{20}$ as follows: face, head, neck/cervical spine, thoracic spine/upper back, sternum/ribs, lumbar spine/lower back, abdomen, pelvis/sacrum/buttock, shoulder/clavicle, upper arm, elbow, forearm, wrist, hand, finger, thumb, hip, groin, thigh, knee, lower leg, Achilles tendon, ankle and foot/ toe injuries. In this study, injuries were defined as overuse injuries as follows: pain that occurred spontaneously without any obvious traumatic events, which led to difficulties in sports activities, and resulted in restriction of the swimmer's participation for at least 1 day beyond the day of injury. The orthopaedic surgeons classified the severity in three stages for each diagnosis (Active: treatment and immediate workup; Follow: need re-examination and follow-up; Inactive: history and resolved problems). In this study, we analysed chronic disorders of Active and Follow. We classified swimmers into two groups (injured group: swimmers who experienced more than one injury; non-injured group: those who did not have injuries).

The items extracted were as follows: total number of injuries by body parts and injury incidence rates from 2002 to 2016; the incidence of injury in the top four body parts calculated for every year; and injury incidence rate by body part for each type of swimming stroke.

\section{The lumbar injury prevention project}

The Japan Swimming Federation introduced the lumbar injury prevention project to the national team in cooperation with JISS in 2008. The project consisted of two components: deep trunk muscle activation training and evaluation of lumbar disc degeneration using MRI.

\section{Intervention and educational components}

For the national team, representative physical therapists provided guidance and conducted workshops on prevention training at the national training camp and at competitions (figure 1). Swimmers were encouraged to perform prevention training during the national training camp and at competitions and in daily exercises in each team. During the training camp and expedition, the physical therapists checked the daily exercises. The roles of the physical therapists were to (1) provide specific instruction to swimmers, and (2) provide verbal feedback to actively encourage players to perform each exercise with good form (eg, trunk positions, hip and lib position). The Japan Swimming Federation published a DVD introducing the preventive training and made it available for purchase and approximately 1000 of them were distributed in 2009. The primary prevention training components are shown in figure 1 . The basis of the exercises is trunk stabilisation which consists of draw-in, front bridge, side bridge and hip lift exercises, and may play an important role in lumbar injury prevention and rehabilitation. $^{21-24}$ These exercises induced contraction of the transverse abdominal muscles and the lumbar multifidus muscle, both of which are important for the prevention of lower back injury. ${ }^{25}$

Details of the exercise are as follows: Front bridge: (A) keep the front bridge for $60 \mathrm{~s}$, (B) front bridge while raising the upper limbs $10 \times 2$ repetitions, $(\mathrm{C})$ front bridge with hip extensions on an unstable surface for $10 \times 2$ repetitions. Hip lift: (D) normal hip lift $10 \times 2$ repetitions, (E) hip lift that raises one leg with a ball in the thigh $10 \times 2$ repetitions, (F) move the lifting leg up and down with one single leg hip lift $10 \times 2$ repetitions. Side bridge: $(G)$ draw-in sideways $10 \times 2$ repetitions, $(\mathrm{H})$ keep the side bridge posture for $3 \mathrm{~s}$ and raise and lower the body side $10 \times 2$ repetitions, (I) raise the trunk and lower the legs by placing the upper leg on the supporter's knee in a side bridge position $10 \times 2$ repetitions (figure 1 ).

Lumbar disc degeneration was analysed using T2-weighted MR images before each international competition as a part of the precompetition medical check-up. Two orthopaedic doctors evaluated disc degeneration according to the Pfirrmann classification ${ }^{26}$ and Grade III and higher were indicative of degeneration. These swimmers received feedback from orthopaedic doctors about the development of intervertebral disc degeneration.

\section{Statistical analysis}

We calculated the incident rate of injuries in the top four sites from 2002 to 2016 every year. 
Front Bridge

A

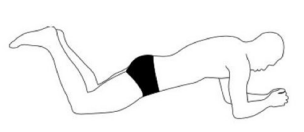

B

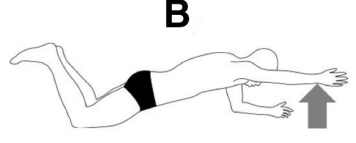

C
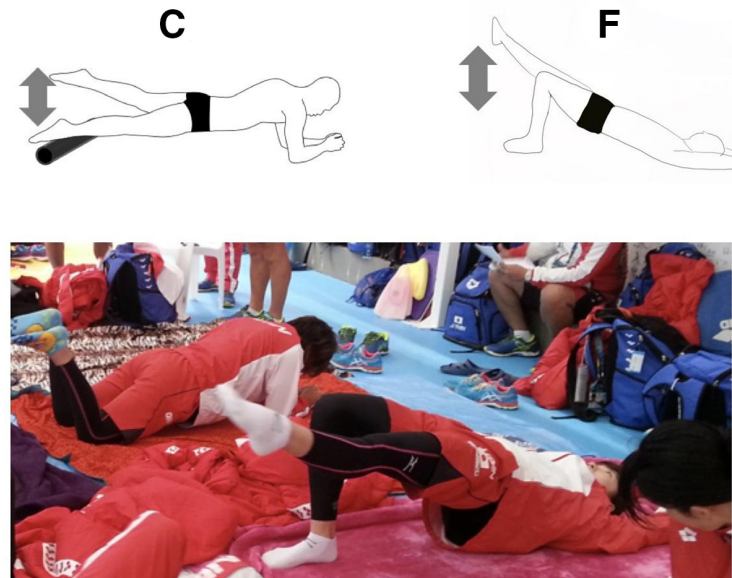

Hip lift

D

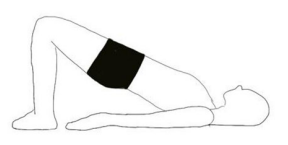

E

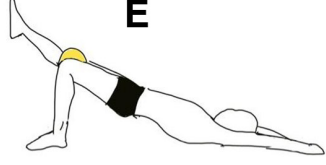

$\mathbf{F}$

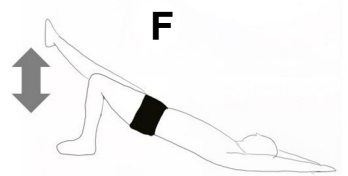

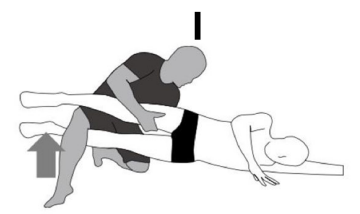

Side Bridge

G
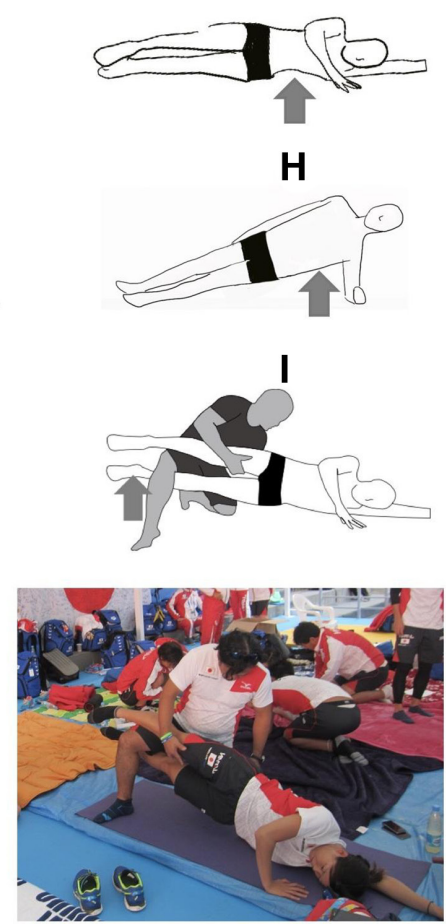

Figure 1 Examples of lumbar injury prevention exercises.

A: Front bridge keeping, B:Front bridge with raising the upper limbs, C: Front bridge with hip extensions on an unstable surface, D: Normal hip lift, E: Hip lift that raises one leg with a ball in the thigh, F: Hip lift moving the lifting leg up and down, G: Side draw-in, H: Side brige keeping, I: Insaide-bridge, raise the trunk and lower the legs by placing the upper leg on the supporter's knee in a side bredge position.

The study consisted of two phases: a 7-year (20022008) observation period and an 8-year (2009-2016) intervention period. The relative risk of lumbar injuries, incidence rate of total injuries and top four sites were compared between the observation period (2002-2008) and the intervention period (2009-2016) using $\chi^{2}$ test. Incidence rates were calculated as the number of injuries per competing athlete and per 100 athletes by body of parts in males, females and total from 2002 to 2016. For incidence rates, 95\% CIs were calculated. Incidence rate of injuries in the top three sites was measured and the comparison between the swimming strokes was performed using $\chi^{2}$ test. Comparison of the incidence rate by sex was done using $\chi^{2}$ test. The average age of each was compared with an unpaired t-test. Statistical significance was set as 0.05. SPSS V.24 (SPSS) was used for all analyses.

\section{RESULTS}

Incidence rate of injuries in the top four sites from 2002 to 2016

Figure 2 shows the trends of the injury rates of the lumbar spine, shoulder, knee and ankle joints-the top four injury sites-over 15 years. A downward trend was observed for lumbar injury from 2002 to 2016. The highest incidence, $33.3 \%$, was observed in 2002. However, the incidence in 2009, the year immediately following the implementation of the lumbar injury prevention project, was the lowest at $5.6 \%$.

Shoulder joint injury incidence was approximately $10 \%$ in 2002-2008, but in 2012 and 2014 it was more than $15 \%$, and the highest, $25.7 \%$, was in 2015 . Thus, an increasing trend in shoulder joint injury has been observed in the recent years.

Knee joint injury incidence was around 5\%-10\% in 2002-2008, but it rapidly increased to $20.7 \%$ in 2010. Subsequently, it was more than $20 \%$ in 2012, 2014 and 2015, and an increasing trend in knee joint injury was

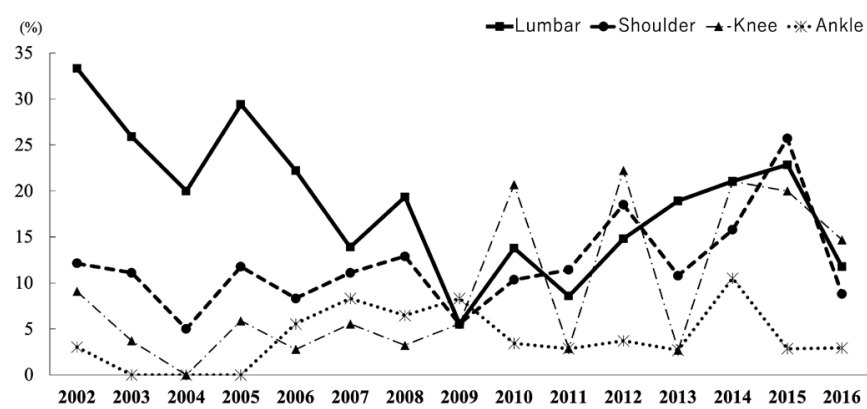

Figure 2 The incidence rates of the top four injuries from 2002 to 2016. 
Table 1 Participant characteristics and number of participants, total injuries and top four sites during observation and intervention periods

\begin{tabular}{|c|c|c|c|c|c|c|}
\hline \multirow[b]{2}{*}{$\begin{array}{l}\text { Prticipants } \\
\text { Characteristics }\end{array}$} & \multicolumn{2}{|c|}{$\begin{array}{l}\text { Observation period } \\
(2002-2008)\end{array}$} & \multicolumn{2}{|c|}{$\begin{array}{l}\text { Intervention period } \\
(2009-2016)\end{array}$} & \multicolumn{2}{|c|}{$\begin{array}{l}\text { P value } \\
\text { (observation vs intervention) }\end{array}$} \\
\hline & Male $(n=121)$ & Female $(n=96)$ & Male $(n=144)$ & Female $(n=127)$ & Male & Female \\
\hline Age, y & $21 \pm 2$ & $21 \pm 3$ & $22 \pm 6$ & $21 \pm 4$ & 0.09 & 0.94 \\
\hline Height, $\mathrm{cm}$ & $178.3 \pm 4.9$ & $166.1 \pm 5.3$ & $178.0 \pm 3.5$ & $164.3 \pm 5.7$ & 0.59 & 0.15 \\
\hline Weight, kg & $72.5 \pm 6.2$ & $57.2 \pm 4.4$ & $72.2 \pm 4.2$ & $57.1 \pm 2.8$ & 0.72 & 0.92 \\
\hline Body mass index & $22.8 \pm 1.3$ & $20.7 \pm 1.1$ & $22.7 \pm 0.3$ & $22 \pm 0.4$ & 0.92 & 0.31 \\
\hline \multicolumn{7}{|c|}{ Injuries during observation and intervention periods } \\
\hline participants, $n$ & 217 & & 271 & & & \\
\hline Total Injuries, n(\%) & $94(43.3)$ & & $122(45.0)$ & & 0.715 & \\
\hline Lumber Injuries, n(\%) & $51(23.5)$ & & $40(14.8)$ & & $0.014^{*}$ & \\
\hline Shoulder Injuries, n(\%) & $22(10.1)$ & & $36(13.3)$ & & 0.286 & \\
\hline Knee Injuries, n(\%) & $10(4.6)$ & & 36 (13.3) & & $0.001^{* *}$ & \\
\hline Ankle Injuries,n(\%) & $8(3.7)$ & & $13(4.8)$ & & 0.548 & \\
\hline
\end{tabular}

Participant characteristics expressed as mean \pm SD.

${ }^{*} p<0.05 ;{ }^{* *} p<0.01$.

noted in recent years. There was no marked change in the ankle joint injury incidence in 2002-2016 and was around 5\%; the highest incidence was 10.5\% in 2014.

\section{Effectiveness of the lumbar injury prevention project}

The demographic characteristics, including age, height, weight and body mass index of the swimmers, are presented in table 1. During the observation and intervention periods, 51 lumbar injuries $(23.5 \%)$ and 40 lumbar injuries $(14.8 \%)$ were recorded, respectively (table 1, figure 3). Lumbar injury incidence decreased significantly during the intervention period $(\mathrm{p}=0.014$, OR $0.564,95 \%$ CI 0.356 to 0.892 ). The relative risk was 0.11 (95\% CI 1.020 to $1.218, \mathrm{p}=0.014)$.

In the observation period, 94 out of 217 swimmers $(43.3 \%)$ experienced some type of injury. In the intervention period, 122 of 271 swimmers $(45.0 \%)$ experienced some type of injury. There was no significant difference

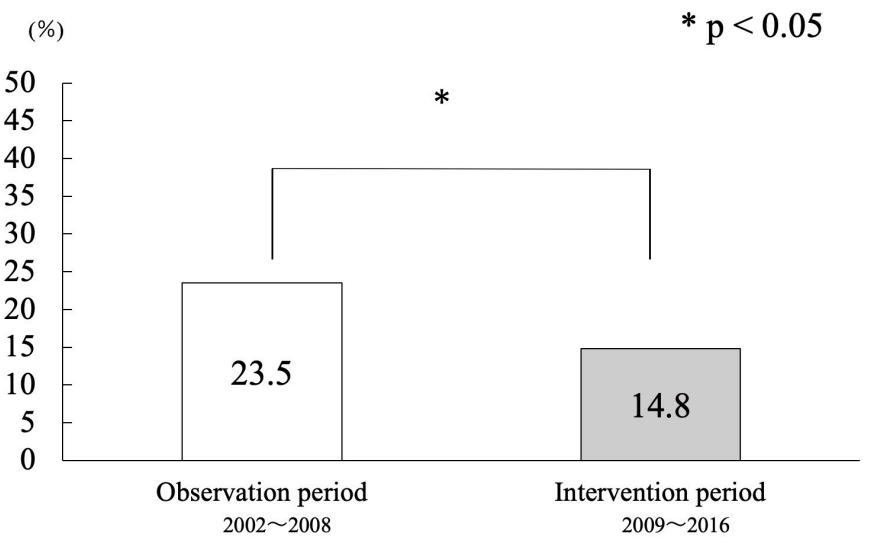

Figure 3 Prevalence of lumbar injuries before and after the start of the project. in the type of injury before and after the project $(\mathrm{p}=0.707$, OR $1.071,95 \%$ CI 0.748 to 1.535$)$. In contrast, the knee injury incidence increased significantly during the intervention period $(\mathrm{p}=0.001$, OR $3.171,95 \%$ CI 1.536 to 6.548$)$. There was no significant difference in the shoulder and ankle injury incidence before and after the project (shoulder: $\mathrm{p}=0.286$, OR $1.358,95 \%$ CI 0.773 to 2.385, ankle: $p=0.548$, OR $1.316,95 \%$ CI 0.536 to 3.236 ; table 1).

\section{Number of injuries and injury rates in each body part}

A total of 283 injuries were recorded for the Japan national swim team from 2002 to 2016. The highest injury rate was observed for the lumbar (total $18.6 \%$, males $15.1 \%$, females $22.9 \%$, table 2), followed by shoulder $(11.9 \%, 10.2 \%, 13.9 \%)$, knee $(9.4 \%, 7.2 \%, 12.1 \%)$ and ankle $(4.3 \%, 2.6 \%, 6.3 \%)$.

\section{Injured parts of the body depending on the type of swimming stroke}

The top three injuries for each swimming stroke were as follows: freestyle $(\mathrm{n}=172)$, lumbar $(16.9 \%, 95 \% \mathrm{CI}$ $16.4 \%$ to $17.3 \%)$, knee $(10.5 \%, 95 \%$ CI $10.1 \%$ to $10.8 \%)$, shoulder $(7.6 \%, 95 \%$ CI $7.3 \%$ to $7.9 \%)$; backstroke $(\mathrm{n}=78)$, lumbar $(24.4 \%, 95 \%$ CI $23.3 \%$ to $25.4 \%)$, shoulder $(23.1 \%, 95 \%$ CI $22.0 \%$ to $24.1 \%)$, ankle $(6.4 \%$, $95 \%$ CI $5.8 \%$ to $7.0 \%)$; breaststroke $(\mathrm{n}=86)$, lumbar $(20.9 \%, 95 \%$ CI $23.3 \%$ to $25.4 \%)$, shoulder $(14.0 \%$, $95 \%$ CI $13.2 \%$ to $14.7 \%)$, knee $(12.8 \%, 95 \%$ CI $12.0 \%$ to $13.6 \%)$; butterfly $(\mathrm{n}=78)$, lumbar $(19.2 \%, 95 \%$ CI $18.2 \%$ to $20.2 \%)$, shoulder $(9.0 \%, 95 \%$ CI $8.3 \%$ to $9.7 \%)$, knee $(6.4 \%, 95 \%$ CI $5.8 \%$ to $7.0 \%)$; individual medley $(\mathrm{n}=74)$, lumbar $(13.5 \%, 95 \%$ CI $12.8 \%$ to $14.3 \%)$, shoulder and knee injury incidence was equal $(10.8 \%, 95 \%$ CI $10.1 \%$ to 


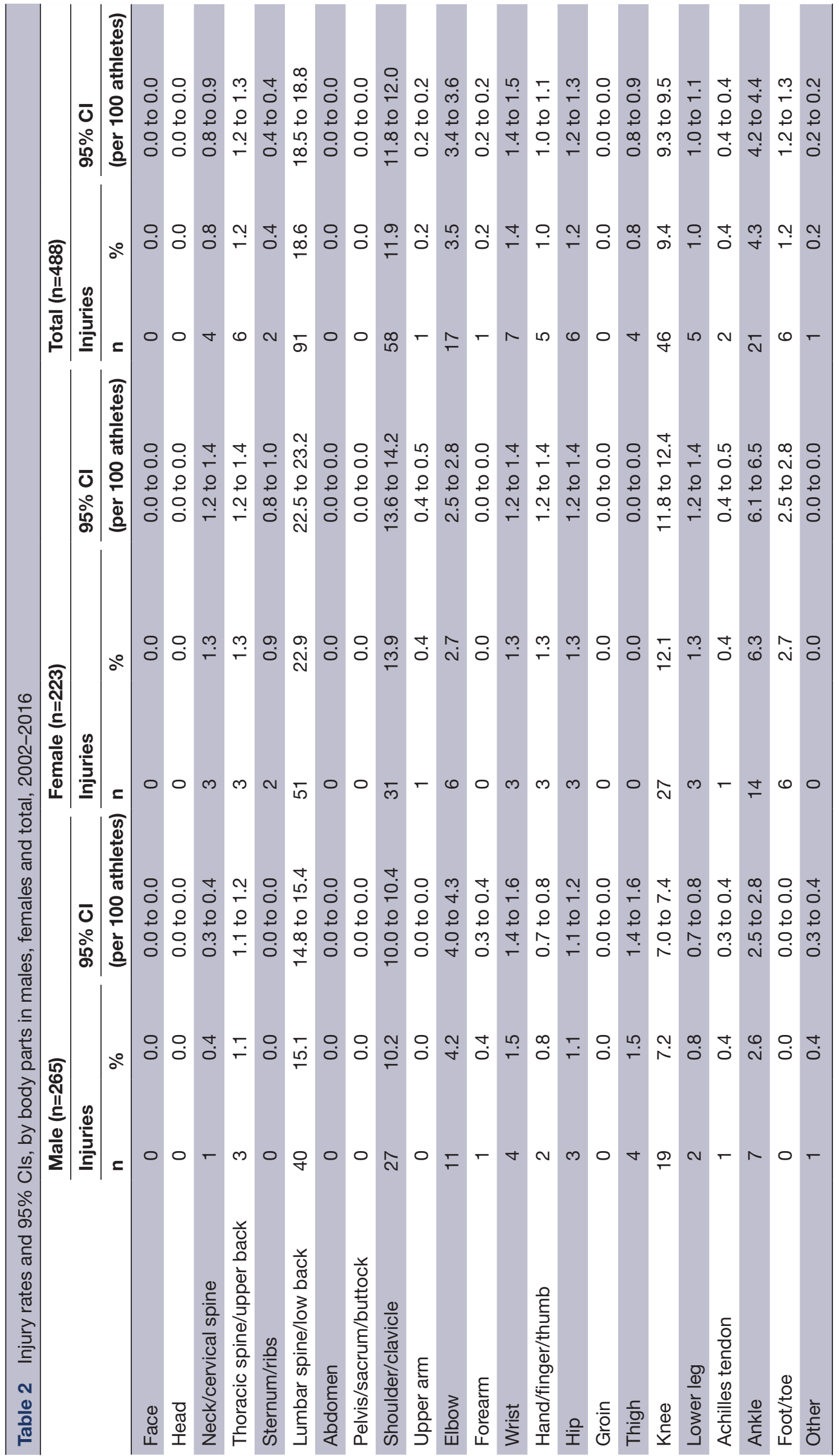




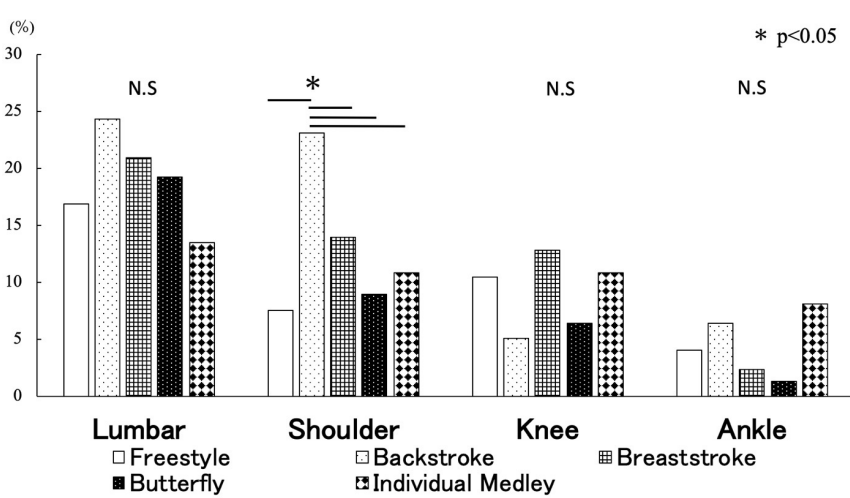

Figure 4 Prevalence of lumbar, shoulder, knee and ankle joint injury by type of stroke. NS, not significant.

$11.5 \%$, each). For all strokes, the lumbar injury was most frequently observed.

Eighteen out of 78 swimmers whose event was backstroke $(23.1 \%)$ experienced shoulder injuries. The shoulder injury rate was significantly higher among backstroke swimmers than among other swimming strokes $(\mathrm{p}=0.009$; figure 4$)$.

\section{Injury rate by sex}

Overall, 100 out of 365 male and 116 out of 223 female swimmers experienced an injury in at least one body part. The injury rate was significantly higher in females $(52.0 \%)$ than in males $(37.7 \%)(\mathrm{p}=0.002)$.

\section{Age of participants in the injured and non-injured groups}

Figure 4 shows the average age of the injured and noninjured groups by sex. The average age of males in the injured group was $22 \pm 3$ years, and the age in the noninjured group was $21 \pm 3$ years. The average age of females in the injured group was $21 \pm 3$ years, and that of females in the non-injured group was $20 \pm 2$ years. The injured group was significantly older than the non-injured group (males, $\mathrm{p}=0.046$; females, $\mathrm{p}=0.002$ ).

\section{DISCUSSION}

In this study, we conducted a survey of the injuries experienced by the Japan national swim team from 2002 to 2016. The prevalence of lumbar injury was significantly lower after the implementation of the prevention project from 2008. Although there are interventional studies regarding the prevention of shoulder joint injuries for swimmers, ${ }^{8} 27$ this was the first comprehensive investigation of the incidence of injuries associated with swimming at the national level over many years, including the incidence after the implementation of the lumbar injury prevention project.

\section{Effectiveness of the lumbar injury prevention project}

The most common site of injury was the lower back, followed by the shoulders and knees. While it has been reported that there are many shoulder injuries in swimming, ${ }^{5-12}$ the possible reasons why there were so many lumbar injuries in this study were: differences in training volume and method, and genetic factors. However, the exact reason was not clear and further study is required.

The introduction of the lumbar injury prevention project in 2008 resulted in a significant decrease in the lumbar injury rate (figure 3 ). The overall injury rate before $(43.3 \%)$ and after $(45.0 \%)$ this project showed no statistically significant difference. However, the lumbar injury rate significantly decreased from $23.5 \%$ to $14.8 \%$ $(\mathrm{p}<0.05)$. Deep trunk muscle training in this project focused on the reinforcement of the deep trunk muscles, such as the transversus abdominis muscle and the multifidus muscles. ${ }^{25}$ The deep trunk muscles contribute to the prevention of lower back injuries. ${ }^{28-30}$ The deep trunk muscle training conducted in this study reveals an immediate effect after intervention exercise, which is the lumbar lordosis angle in water motion. ${ }^{31}$ Therefore, this project was effective in the prevention of lumbar injuries. During the interventional period of the present study, we consider that the strengthened deep trunk muscles contributed to the stabilisation of the lumbar spine during swimming movements and reduced the number of lumbar injuries.

Furthermore, this study provided an intervention protocol and education. The current evidence suggests that exercise in combination with education is effective for preventing low back pain. ${ }^{19}$ Since we were not able to have a control group for with and without early detection and education in the prevention project after 2008, comparisons were therefore made by using the period before 2008, in which no education of risk management by disc degeneration check using MRI served as the control group. However, we believe that exercise intervention and education of risk management by disc degeneration check using MRI, along with the importance of deep trunk muscle exercises (not implemented before 2008), were also factors contributing to this reduced incidence.

\section{Injury trends over 15 years}

Shoulder joint injury incidence increased in swimmers in recent years. The backstroke swimmers have more shoulder injury than other strokes. Impingement of the shoulder joint occurred at shoulder joint elevation and internal rotation. ${ }^{32}$ Compared with other strokes, the backstroke forces the humeral internal rotation sprain in the upper limb elevation during the catching motion. If swimmers perform a catch motion from the moment they enter the water with insufficient mobility of the thoracic vertebrae, impingement is likely to occur due to excessive inner rotation of the scapulobrachial joint. ${ }^{33}$ The backstroke swimmers may need to acquire higher thoracic vertebrae and rib cage mobility as opposed to other strokes.

The knee joint incidence also tended to increase over 15 years. Soder et al reported that abnormal knee injury findings were observed in the MRI images in $69.2 \%$ of the swimmers, regardless of pain in the knee joints. ${ }^{34}$ Most reported pain around the patella and the patellarfemoral joint. ${ }^{34}$ In this study, we did not have MRI on all 
knee injuries. However, most of orthopaedic surgeons' diagnosis was patellofemoral pain syndrome, which accounted for most of the knee joint injuries, where the knee joint is affected by the knee joint extension motion, such as the start motion performed during swimming. The increase in the knee joint injury incidence became noticeable in this study for the period 2008-2010, during which the start inclination angle changed from $7.5^{\circ}$ to $10^{\circ}$ and with starting block. The time when the start block was introduced coincided with the period when the increase in the incidence of knee joint injuries was noted. Studies have reported that the kick-start using this inclined starting block allows a shorter block time, a higher horizontal take-off velocity and better timings for $15 \mathrm{~m}$ compared with the track start. ${ }^{35}$ Therefore, there is a possibility that the load applied to the joint increases as the floor reaction force increases.

\section{Risk factors for injury}

In this study, the risk factors for injury were female sex and older age. The higher injury rate in female swimmers is consistent with the results of previous studies. ${ }^{6736}$ Further studies are required to examine the amount of training, the intensity of training and fatigue level, and clarify why women often have overuse injuries. Regarding older age, findings indicate that there was no relationship between shoulder joint injury and age. ${ }^{9} 153738$ In contrast, a long history of participation in swimming competitions was a risk factor for injury. ${ }^{20}{ }^{21}$ In this study, age was a risk factor because there was a possibility that an older age may correlate with a longer history of training load. Since the incidence of injuries is greater in female swimmers, and in swimmers of an older age, the rate of injuries will be reduced in the future by taking preventive measures especially for young women. Consequently, we recommend that lumbar injury prevention intervention commences at a young age to mitigate the increasing incidence of lumbar injuries in female athletes as they mature.

\section{Limitations}

A limitation of this study was that we could not calculate the athlete exposure. It is important to analyse the athlete exposure separately according to the diagnoses, as noted in the study by Zachary ${ }^{6}$ to determine the cause of the injury. However, athlete exposure was substituted by the injury rate per 100 registered athletes based on the report of Mountjoy in this study. ${ }^{2}$ In the future, athlete exposure should be calculated and detailed analysis must be conducted. In this study, it was also impossible to establish a control group. The reason for this was that all the subjects in this study were national team swimmers, and could not be distinguished between swimmers. Therefore, in this study, we set up two groups before and after implementation of the prevention project.

Furthermore, we could not calculate the compliance rate of training interventions. During this intervention period, the physiotherapists supervised swimmer's exercise techniques at major international competitions and national training camps every day, so that swimmers were familiar with the proper exercise techniques and understood the importance of the exercises. In particular, knee, shoulder and lower back injuries increased from 2012 to 2015, which may be related to the change of training such as high-intensity training and weight training, but the causal relationship is unknown.

In the future, we would like to survey the incidence of injuries based on athlete exposure and type of training and investigate the effect of injury prevention intervention for the shoulder and knee joints, because the incidence of shoulder and knee joint injuries was found to be increasing as per an injury surveillance study.

\section{CONCLUSION}

This 8-year prospective intervention study indicated that the lumbar injury prevention project significantly reduced low back injury incidence in the Japan national team swimmers. The incidence of knee joint and shoulder joint injuries showed an increasing trend, revealing a need to prevent these injuries. Notably, shoulder injuries were significantly higher in the backstroke. As both female and older athletes have a higher risk of injury, prevention interventions should commence at a young age, especially for female athletes.

Acknowledgements The authors highly appreciate the Japan Swimming Federation and the Japan Institute of Sports Sciences.

Contributors YM: first author, substantial contributions to conception and design, data collection, interpretation of results, drafting and revising the manuscript and final version to be published. KoK: corresponding author, substantial contributions to conception and design, data analysis, interpretation of results, drafting and revising the manuscript and final version to be published. $\mathrm{MH}, \mathrm{KeK}, \mathrm{NH}, \mathrm{KU}, \mathrm{HA}$ substantial contributions to data collection, revising the manuscript and approval of final version to be published.

Funding The authors have not declared a specific grant for this research from any funding agency in the public, commercial or not-for-profit sectors.

Competing interests None declared.

Patient consent for publication Not required.

Provenance and peer review Not commissioned; externally peer reviewed.

Data availability statement No data are available.

Open access This is an open access article distributed in accordance with the Creative Commons Attribution Non Commercial (CC BY-NC 4.0) license, which permits others to distribute, remix, adapt, build upon this work non-commercially, and license their derivative works on different terms, provided the original work is properly cited, appropriate credit is given, any changes made indicated, and the use is non-commercial. See: http://creativecommons.org/licenses/by-nc/4.0/.

ORCID iD

Yuiko Matsuura https://orcid.org/0000-0002-3397-1140

\section{REFERENCES}

1 Schroeder AN, Comstock RD, Collins CL, et al. Epidemiology of overuse injuries among high-school athletes in the United States. J Pediatr 2015;166:600-6.

2 Mountjoy M, Junge A, Benjamen S, et al. Competing with injuries: injuries prior to and during the 15th FINA World Championships 2013 (aquatics). Br J Sports Med 2015;49:37-43.

3 Prien A, Mountjoy M, Miller J, et al. Injury and illness in aquatic sport: how high is the risk? A comparison of results from three FINA World Championships. Br J Sports Med 2017;51:277-82. 
4 Soligard T, Steffen K, Palmer D, et al. Sports injury and illness incidence in the Rio de Janeiro 2016 Olympic summer games: a prospective study of 11274 athletes from 207 countries. Br J Sports Med 2017:51:1265-71.

5 Wolf BR, Ebinger AE, Lawler MP, et al. Injury patterns in division I collegiate swimming. Am J Sports Med 2009;37:2037-42.

6 Kerr ZY, Baugh CM, Hibberd EE, et al. Epidemiology of national collegiate athletic association men's and women's swimming and diving injuries from 2009/2010 to 2013/2014. Br J Sports Med 2015:49:465-71.

7 Mountjoy M, Junge A, Alonso JM, et al. Sports injuries and illnesses in the 2009 FINA World Championships (Aquatics). Br J Sports Med 2010;44:522-7.

8 Lynch SS, Thigpen CA, Mihalik JP, et al. The effects of an exercise intervention on forward head and rounded shoulder postures in elite swimmers. Br J Sports Med 2010;44:376-81.

9 Tate A, Turner GN, Knab SE, et al. Risk factors associated with shoulder pain and disability across the lifespan of competitive swimmers. J Athl Train 2012;47:149-58.

10 Hibberd EE, Myers JB. Practice habits and attitudes and behaviors concerning shoulder pain in high school competitive Club swimmers. Clin J Sport Med 2013;23:450-5.

11 McMaster WC. Shoulder injuries in competitive swimmers. Clin Sports Med 1999;18:349-59.

12 Weldon EJ, Richardson AB. Upper extremity overuse injuries in swimming. A discussion of swimmer's shoulder. Clin Sports Med 2001;20:423-38.

13 Bak K. The practical management of swimmer's painful shoulder: etiology, diagnosis, and treatment. Clin J Sport Med 2010;20:386-90.

14 Wanivenhaus F, Fox AJS, Chaudhury S, et al. Epidemiology of injuries and prevention strategies in competitive swimmers. Sports Health 2012;4:246-51.

15 Chase KI, Caine DJ, Goodwin BJ, et al. A prospective study of injury affecting competitive collegiate swimmers. Res Sports Med 2013;21:111-23.

16 Hangai MK, Okuwaki T. Sports injuries in elite swimmer. Jpn J Orthop Sports Med 2010;30:161-6.

17 Kaneoka K, Shimizu K, Hangai M, et al. Lumbar intervertebral disk degeneration in elite competitive swimmers: a case control study. Am J Sports Med 2007;35:1341-5.

18 Hangai M, Kaneoka K, Hinotsu S, et al. Lumbar intervertebral disk degeneration in athletes. Am J Sports Med 2009;37:149-55.

19 Steffens D, Maher CG, Pereira LSM, et al. Prevention of low back pain: a systematic review and meta-analysis. JAMA Intern Med 2016;176:199-208.

20 Junge A, Engebretsen L, Alonso JM, et al. Injury surveillance in multi-sport events: the International Olympic Committee approach. Br J Sports Med 2008;42:413-21.

21 Comerford MJ, Mottram SL. Functional stability re-training: principles and strategies for managing mechanical dysfunction. Man Ther 2001;6:3-14.

22 Butcher SJ CB, Chilibeck PD, Spink KS, et al. The effects of preseason trunk muscle train- ING on low-back pain occurrence in women collegiate gymnasts. $J$ Orthop Sports Phys Ther 2007:37:223-31.

23 O'Sullivan PB, Phyty GD, Twomey LT, et al. Evaluation of specific stabilizing exercise in the treatment of chronic low back pain with radiologic diagnosis of spondylolysis or spondylolisthesis. Spine 1997;22:2959-67.

24 Rasmussen-Barr E, Ang B, Arvidsson I, et al. Graded exercise for recurrent low-back pain: a randomized, controlled trial with 6-, 12-, and 36-month follow-ups. Spine 2009;34:221-8.

25 Okubo Y, Kaneoka K, Imai A, et al. Electromyographic analysis of transversus abdominis and lumbar multifidus using wire electrodes during lumbar stabilization exercises. J Orthop Sports Phys Ther 2010;40:743-50.

26 Pfirrmann CW, Metzdorf A, Zanetti M, et al. Magnetic resonance classification of lumbar intervertebral disc degeneration. Spine 2001;26:1873-8.

27 Kluemper M, UhI T, Hazelrigg $\mathrm{H}$. Effect of stretching and strengthening shoulder muscles on forward shoulder posture in competitive swimmers. J Sport Rehabil 2006;15:58-70.

28 Durall CJ, Udermann BE, Johansen DR, et al. The effects of preseason trunk muscle training on low-back pain occurrence in women collegiate gymnasts. J Strength Cond Res 2009;23:86-92.

29 Harringe ML, Nordgren JS, Arvidsson I, et al. Low back pain in young female gymnasts and the effect of specific segmental muscle control exercises of the lumbar spine: a prospective controlled intervention study. Knee Surg Sports Traumatol Arthr 2007;15:1264-71.

30 Hides JA, Stanton WR, McMahon S, et al. Effect of stabilization training on multifidus muscle cross-sectional area among young elite cricketers with low back pain. $J$ Orthop Sports Phys Ther 2008;38:101-8.

31 Matsuura Y, lizuka S, Koizumi K, et al. Immediate effects of the deep trunk muscle training on lumbar spine alignment during swimming. $J$ Sport Health Sci 2019;17:25-31.

32 Yamamoto N, Muraki T, Sperling JW, et al. Impingement mechanisms of the Neer and Hawkins signs. J Shoulder Elbow Surg 2009;18:942-7.

33 Tovin BJ. Prevention and treatment of swimmer's shoulder. N Am J Sports Phys Ther 2006;1:166-75.

34 Soder RB, Mizerkowski MD, Petkowicz R, et al. MRI of the knee in asymptomatic adolescent swimmers: a controlled study. $\mathrm{Br} J$ Sports Med 2012;46:268-72.

35 Ozeki SS K, Taguchi M, Takise S. Kicking the back plate of the starting block improves start phase performance in competitive swimming. eProceedings of the 30th conference of the international society of biomechanics in sports 2012:373-6.

36 Sallis RE, Jones K, Sunshine S, et al. Comparing sports injuries in men and women. Int J Sports Med 2001;22:420-3.

37 Harrington S, Meisel C, Tate A. A cross-sectional study examining shoulder pain and disability in division I female swimmers. J Sport Rehabil 2014;23:65-75.

38 Su KPE, Johnson MP, Gracely EJ, et al. Scapular rotation in swimmers with and without impingement syndrome: practice effects. Med Sci Sports Exerc 2004;36:1117-23. 